\section{Maps and Survey}

By Arthur R. Hinks. Fourth edition. Pp. xiv $+301+$ 28 plates. (Cambridge: At the University Press, 1942.) 16s. net.

AANY of the older readers of NATURE will 1 remember the thrills of excitement when the latest traveller returned to Great Britain with the story of some great discovery, but with a very meagre little map, as the secrets of the surface of the world were gradually unfolded. That epoch is now ended, but the art of surveying and of the making of maps continues to improve.

The issue of a fourth edition of Hinks's "Maps and Survey" is welcome, though, owing to military necessities, all the newer elements of military surveys cannot even be mentioned; Chapter 12, on photographic, including air, surveys, being left as it was nine years ago. The additions and corrections collected in Chapter 14 would have been more useful had they been printed on one side of the paper only, so that they could have been cut out and pasted on the appropriate page.

While the surveyor may learn to survey from Close's "Text-book of Topographical Surveying", his education would be incomplete without Hinks's book. The insoluble problem of the spelling of names is well treated, numerous difficult cases being quoted, notably that of the Grampians being called by the Russians Grampianski Gari, while we British in our turn are just as bad. The device mentioned on p. 47 of stamping typed names on to the drawing paper. was the regular method employed by the Survey of India on all its maps except for engraved small-scale maps.

While methods of survey are rightly the preserve of the professional surveyor, the resultant map is essentially for map-users; the general public, therefore, is fully justified in making eriticisms and suggestions as to the form, style and scales of maps they require. It is curious to read in these war days that it was the 1745 rebellion that made the British Government realize the need for accurate maps and was the cause of the inauguration of regular surveys in Great Britain. Even for a non-surveyor, this book, or at least the non-technical parts, is well worth reading.

What Price Alcohol?

A Practical Discussion of the Causes and Treatment of Alcoholism. By Dr. Robert S. Carroll. Pp. xv+ 362. (New York: The Macmillan Company, 1941.) 12s. $6 d$. net.

TNDER this somewhat unconventional title Dr. Robert S. Carroll, founder and medical director of the Highland Hospital, North Carolina, deals with the alcohol problem mainly from the psychiatrist's point of view. The book, which contains a preface by Dr. Adolf Meyer, emeritus professor of psychiatry at Johns Hopkins University, is divided into three sections entitled respectively "Why Alcohol ?", "What Price Alcohol ?" and "Alcohol or Man ?" Recognizing as he does that there is no specific treatment for alcoholism owing to the great variety among the sufferers from this condition, the author advocates the elaborate study of each individual case, laying special stress on the importance of a daily association of the psychiatrist with the patient. $\mathrm{He}$ forecasts that the future progress of the campaign against alcoholism will be effected by an alliance of scientific searchers after truth and the avoidance of declamations against strong drink, while he suggests the ereation of courses of mental hygiene for all types of schools and publicity sponsored by the State.

Other subjects discussed in this work are the biochemistry of alcohol, alcoholism in women, the relation of alcohol to sexual life, the treatment of benign cases and, most important of all, re-education. Drug treatment in the form of sedatives, morphia and its associates are regarded as unnecessary. The work is illustrated by the description of cases from the author's practice, some of which he has studied for fifty years.

\section{The Life of Sir William Osler}

By Harvey Cushing. Pp. xviii $+1417+12$ plates. (London, New York and Toronto : Oxford University Press, 1940.) 21s, net.

THE life of William Osler by Harvey Cushing, published in 1925, has held its place, and must continue to do so, as one of the greatest of medical biographies. The book under review consists of one volume instead of two, and contains, with unaltered text, only eleven of the forty-seven original illustrations. For these reasons it is less expensive than its forerunner and may well enjoy a wider circulation among medical students, to whose purses it is intended especially to appeal.

Cushing described his two volumes as a compilation of records put together in the hope that the story of Osler's life would tell itself through what he put on paper. Through this medium his personality, spirit and character were certainly revealed to the reader, but no attempt was made to appraise his professional accomplishments, considerable as they must prove to be when the final count is made.

Whether Drs. John F. Fulton and W. W. Francis, who are responsible for this new edition, will succeed in introducing it to as many students as they hope for may be in doubt. Even a single volume of nearly fourteen hundred closely printed pages is a formidable task to tackle, and yet another "Boswell" may one day abridge the text for another generation without decreasing its attraction and historical interest.

Both Osler and Cushing, who were intimate friends during twenty-five years, played prominent parts in the most productive era of clinical medicine in North America, the former by his unequalled personal charm and inspired leadership, the latter by his solid contributions to the advance of knowledge.

\section{Allergy}

Strangest of all Maladies. By Dr. Warren T. Vaughan. (Advancement of Science Series, No. 2.) Pp. 160. (London, New York and Melbourne: Hutchinson's Scientific and Technical Publications, 1942.) 10s. $6 d$. net.

7 HIS little book, as the subtitle states, is "a popular study of the causes and methods of treating asthma, hay fever, urticaria and other allergic diseases". Though primarily intended for the general reader, the work will be of service to many medical practitioners, who will be surprised by the author's interpretation of phenomena as allergic which they had previously attributed to some other cause. Examples of the kind are drowning and certain physical expressions of unrequited affection. The book is written in a humorous style, and the text is liberally interspersed by half-tones and line drawings of a correspondingly facetious character, which should facilitate the comprehension of so difficult a subject.
J. D. R. 